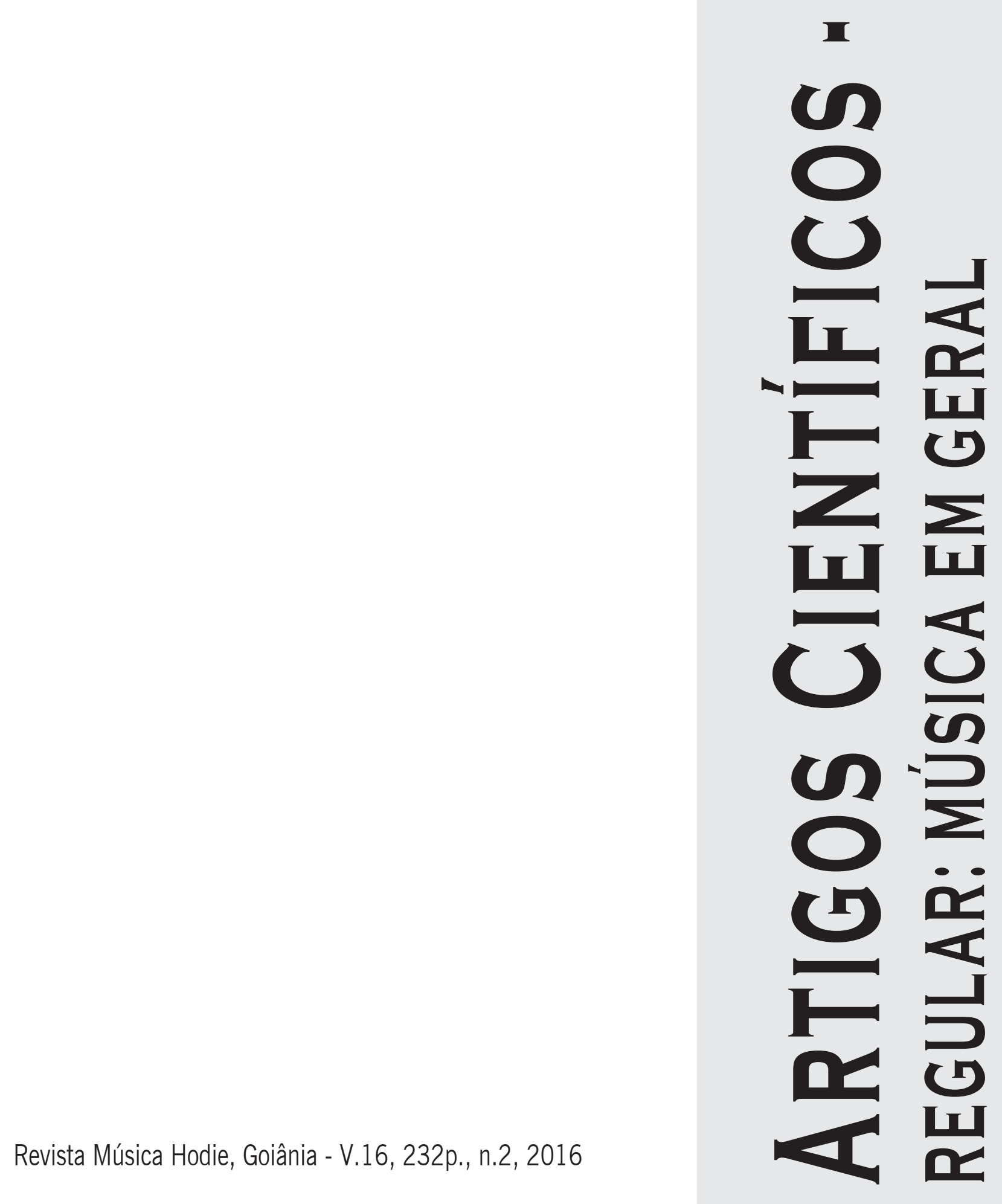




\title{
O Método Suzuki e o folclore brasileiro: proposta de uma abordagem de ensino para os instrumentos de cordas
}

\author{
Gláucia de Andrade Borges (Universidade do Estado de Minas Gerais, Belo Horizonte, MG, Brasil) \\ gbviolino@yahoo.com.br
}

\begin{abstract}
Resumo: O objetivo deste artigo é apresentar uma proposta de ensino para os instrumentos de cordas que incorpore a abordagem pedagógica de Shinichi Suzuki e a utilização de canções folclóricas brasileiras e, para complementá-la, os princípios de bom uso do corpo defendidos por Paul Rolland. Aspectos relacionados ao ensino de cordas no Brasil, às metodologias de ensino de Suzuki e de Rolland e os benefícios da inclusão do folclore brasileiro na instrução básica serão discutidos sucintamente. O material pedagógico e as etapas das pesquisas realizadas que o geraram serão descritos. Pressupõe-se que a aplicação dessa proposta poderá facilitar a assimilação do conteúdo técnico-musical e dos mecanismos básicos do instrumento.
\end{abstract}

Palavras-chave: Ensino dos instrumentos de cordas; Folclore brasileiro; Método Suzuki; Paul Rolland.

The Suzuki Method and the Brazilian folklore: proposal for a teaching approach for string instruments

Abstract: This article has the objective to present an approach for basic teaching of string instruments that incorporates the pedagogical approach of Shinichi Suzuki and the use of Brazilian folk songs and, to complement it, the principles of good use of the body advocated by Paul Rolland. Aspects related to the teaching of string instruments in Brazil, the teaching methodologies of Suzuki and Rolland and the benefits of inclusion of Brazilian folklore in basic education will be discussed briefly. The pedagogical material developed and steps of researches conducted that generated it will be described. It presupposes that the application of this proposal could facilitate the assimilation of technical and musical content and the basic mechanisms of the instrument.

Keywords: Teaching of string instruments; Brazilian folklore; Suzuki Method; Paul Rolland.

El Método Suzuki y folclore de brasil: propuesta de un enfoque de enseñanza para instrumentos de cuerda

Resumen: El objetivo de este trabajo es presentar una propuesta educativa para los instrumentos de cuerda, incorporando el enfoque pedagógico de Shinichi Suzuki y el uso de las canciones populares de Brasil y de complementarlo, los principios del buen uso del cuerpo defendidas por Paul Rolland. Aspectos relacionados con la enseñanza de las cuerdas en Brasil, las metodologías de enseñanza de Suzuki y Rolland, y los beneficios de la inclusión del folclore brasileño en la educación básica se discutirán brevemente. Material de formación y etapas de la investigación llevaron a cabo que se describirá genera. Se presupone que la aplicación de esta propuesta podría facilitar la asimilación del contenido técnico y musical y la mecánica básica del instrumento.

Palabras clave: Enseñanza de instrumentos de cuerda; Folclore brasileño; Suzuki Method; Paul Rolland.

Detectou-se, ainda em 1992, que a formação e a profissionalização do aluno de cordas brasileiro sofrem influência em diversos aspectos, estando o principal deles relacionado com o ensino básico (SCOGGIN, 2003). O ensino infantil básico dos instrumentos de cordas requer organização pedagógica e ambiente com alto nível de motivação para que o aluno se interesse pelo seu aprendizado e pratique com frequência. Essa premissa norteou a autora na busca de soluções para essa questão crítica no cenário brasileiro. As pesquisas intituladas O Método Suzuki e a música tradicional mineira no ensino de violino e O Método Suzuki e o folclore brasileiro no ensino dos instrumentos de cordas, realizadas entre 2003 e 2006 e entre 2010 e 2012, respectivamente, foram desenvolvidas como resultado dessa busca. ${ }^{1}$

A abordagem de ensino proposta abrange as seguintes linhas de ação: utilização do repertório exclusivamente brasileiro, seguindo a abordagem de conceitos técnico-musicais introduzidos no repertório do Método Suzuki; apresentação do repertório desenvolvido em três formações instrumentais distintas, para promover a prática da música de câmara; inclusão de princípios do Método Suzuki relativos ao ensino, prática e performance do instrumento; e inclusão de atividades que introduzam e desenvolvam, desde os primeiros es- 
tágios do aprendizado, hábitos posturais e técnicos saudáveis, baseados na metodologia de ensino de Paul Rolland. Esse conjunto de ações busca disponibilizar para o aluno de nível básico um material divertido e abrangente, que atue na prevenção de maus hábitos e no desenvolvimento sólido de habilidades técnicas e musicais, fundamentais a instrumentistas de níveis intermediário e avançado.

Os problemas relacionados ao ensino dos instrumentos de cordas no Brasil, as abordagens de ensino de Shinichi Suzuki e de Paul Rolland, a importância da prática da música de câmara, os benefícios da inclusão do folclore na educação musical e as etapas das pesquisas citadas serão apresentados sucintamente. A elaboração e descrição do repertório, a abordagem do material didático e sua apresentação final serão descritas detalhadamente.

\section{Problemas do ensino dos instrumentos de cordas no Brasil}

A formação de músicos instrumentistas de cordas é problemática no Brasil devido a vários fatores, dentre os quais podemos destacar quatro: difusão deficiente do ensino da música; reduzido número de crianças que estudam violino, viola, violoncelo ou contrabaixo; desistência; e falta de continuidade do ensino (SCOGGIN, 2003, p. 26). Faz-se necessário desenvolver estratégias para captação de um maior contingente de alunos e mantê-los motivados durante o período de aprendizagem básica do instrumento, a fim de que prossigam estudando e se profissionalizem.

Um fator de desmotivação do aluno iniciante brasileiro é a origem estrangeira da maioria dos livros de estudo para os instrumentos de cordas utilizados no Brasil (BORGES-SCOGGIN, 1993, p. 142). Quase todos esses livros utilizam material folclórico do próprio país, ${ }^{2}$ pouco conhecido do nosso povo, estabelecendo certo distanciamento entre o aprendizado do instrumento, a nossa cultura e a experiência musical de nosso aluno. A maneira proposta para estimular a criança brasileira a estudar um instrumento de cordas foi o emprego de uma literatura e uma linguagem musical com que ela estivesse familiarizada. A motivação do aluno, fator de constante preocupação do professor, pode ser maximizada por meio de um repertório familiar (SCOGGIN, 2003, p. 28) e, consequentemente, divertido e eficiente para o iniciante.

Foram encontrados alguns exemplos do uso do folclore brasileiro como material pedagógico para os instrumentos de cordas. Porém, nenhuma dessas iniciativas explora o uso ordenado e criterioso de cantigas brasileiras, seguindo-se a mesma ordem progressiva dos conceitos técnico-musicais apresentados no repertório do Método Suzuki.

Observou-se $^{3}$ que o desenvolvimento técnico dos alunos recém-ingressados nos cursos de graduação possui lacunas referentes à técnica básica do instrumento. Além disso, esses jovens frequentemente apresentam problemas de tensão excessiva que interferem na postura corporal; nos padrões de movimentos; na ação da mão esquerda, como em mudanças de posição e vibrato; e na condução do arco, como na execução, início e finalização dos golpes de arco. Alguns desses problemas podem culminar em dores e distúrbios médicos. O estudo de Alves (2008, p. 4) alerta para o crescente número de violinistas buscando tratamento para suas disfunções físicas a partir de 2002, incluindo alunos universitários. Essas deficiências físicas e técnicas podem ser amenizadas se houver atividades que enfatizem padrões de movimento saudáveis nos estágios iniciais do aprendizado básico, a exemplo da metodologia desenvolvida por Rolland. 


\section{O Método Suzuki}

De acordo com Shinichi Suzuki (1983, p. 1), idealizador do Método Suzuki ${ }^{4}$, qualquer criança é capaz de desenvolver habilidades em um nível elevado se metodologias adequadas forem aplicadas no treinamento. Segundo ele, a língua materna é um "método educacional perfeito" (SUZUKI, 1983, p. 2), em que o aprendizado ocorre com fluência e naturalidade, sem dificuldades ou fracassos. No processo inicial do aprendizado da língua, a criança ouve as mesmas palavras diversas vezes até ser capaz de pronunciá-las, muito antes de aprender a ler e escrever.

No Método Suzuki, a criança aprende a tocar um instrumento da mesma maneira que aprende sua língua materna. Os alunos de instrumento são incentivados a ouvir, diariamente, as peças do repertório para que possam se familiarizar com elas (STARR, 2000, p. 7). Assim, ao tocar as músicas, já internalizaram seus padrões rítmicos e melódicos automaticamente. Cabe ao professor, por meio de demonstrações e ordens verbais, ensinar ao aluno os mecanismos de execução de cada peça no instrumento, encorajando-o a imitá-lo (LANDERS, 1995, p. 13) e a tocar de memória o repertório aprendido, inúmeras vezes. A escuta diária do repertório em estudo auxiliará no desenvolvimento da percepção auditiva da criança e na memorização da peça, já que a instrução inicial se faz por ouvido, sem a utilização de notação musical (STARR, 2000, p. 7). Pode-se destacar dois aspectos da abordagem de ensino do Método Suzuki que contribuem para elevar o nível de motivação dos alunos. São eles: incorporação de atividades coletivas e aprendizado da técnica por meio do repertório (LANDERS, 1995, p. 17).

\section{A metodologia de ensino de Paul Rolland}

Na década de 1960, a abordagem de ensino de Paul Rolland tornou-se internacionalmente conhecida a partir de um projeto de pesquisa em cordas realizado junto à Universidade de Illinois, Estados Unidos. A metodologia se desenvolveu em torno da hipótese de que "o treinamento de movimentos corporais, planejado para liberar o aluno de tensões excessivas, poderia ser introduzido dentro de um plano de ensino organizado" (ROLLAND, 1986, p. 1). Convicto da importância desse treinamento para o futuro desenvolvimento técnico do aluno, o pedagogo acrescenta que "esse plano, a longo prazo, resultaria em um aprendizado mais rápido e em uma melhor performance em todos os aspectos do ensino" (ROLLAND, 1986, p. 1). Os primeiros resultados da aplicação desses princípios podem ser observados na série de vídeos The Teaching of Action in String Playing (ROLLAND, 2008), gravados após dois anos e meio de instrução.

De acordo com Rolland (1986, p. 6),

Os alunos demonstraram convincentemente que a ênfase na postura, na posição correta e na liberdade de movimento, de fato, resultou em uma performance viva e expressiva, em uma qualidade de som e em uma técnica melhor que aquelas geralmente encontradas em turmas de nível intermediário.

Os princípios e os materiais musicais desse projeto foram, primeiramente, desenvolvidos para o violino e a viola. Posteriormente, foram utilizados, com alguns ajustes, no ensino do violoncelo e do contrabaixo (ROLLAND, 1986, p. 1). Rolland propõe inúmeras atividades que promovem a flexibilidade e o equilíbrio do corpo e suas partes, além de introduzirem precocemente conceitos técnicos que contribuirão para o futuro desenvolvimento das respectivas técnicas. A inclusão das atividades elaboradas por Rolland na abordagem 
proposta busca prevenir a absorção e a consolidação dos maus hábitos posturais e técnicos frequentemente relacionados com problemas de tensão excessiva e padrões de movimentos inadequados detectados nos alunos de nível básico, intermediário e avançado.

\section{A prática da música de câmara}

A prática da música de câmara promove o rápido desenvolvimento de habilidades como a escuta, a consciência e a percepção das partes e do todo, a capacidade de resposta e a flexibilidade do instrumentista. Essa experiência pode ser desenvolvida desde os primeiros estágios do aprendizado com a inclusão de formações camerísticas tradicionais como duos, trios, quartetos e quintetos, dentre outros, na abordagem de ensino (BORGES-SCOGGIN, 1993, p. 86). Por constituir a base dos naipes de cordas da orquestra, seja ela de câmara ou sinfônica, o quinteto de cordas oferece uma experiência ainda mais ampla e prepara o jovem aprendiz para a performance em orquestras. A habilidade de tocar uma parte específica e se encaixar dentro de um grupo maior, compreendendo o contexto musical em que se está inserido, pode ser desenvolvida e aprimorada por meio dessa experiência.

Um dos principais campos de trabalho para o instrumentista de cordas são as orquestras (BORGES-SCOGGIN, 1993, p. 151). Portanto, a educação musical e o desenvolvimento técnico do aluno de instrumento devem objetivar uma preparação, a longo prazo, voltada para a performance orquestral (BORGES-SCOGGIN, 1993, p. 88). A abordagem de ensino proposta procurou implementar a prática da música de câmara por meio de duos com piano, duos de violinos, violas, violoncelos e contrabaixos e quintetos de cordas, visando a uma preparação para o futuro campo de trabalho do instrumentista de cordas de uma forma lúdica e prazerosa. A possibilidade de interagir com os colegas ao tocar em um grupo camerístico ou orquestral pode ser uma das principais fontes de motivação para a continuidade do estudo. Além disso, se bem orientado, o trabalho conjunto sedimentará o conhecimento adquirido no aprendizado individual com o professor.

\section{A utilização do folclore brasileiro}

As cantigas folclóricas são utilizadas frequente e extensamente em metodologias de educação musical por todo o mundo. O compositor Zoltán Kodaly, por exemplo, desenvolveu uma metodologia para ensinar música baseada no folclore húngaro. Segundo ele, a utilização de canções cantadas na língua materna contribui para a "formação de valores musicais" (SILVA, 2013, p. 57). De acordo com Edgar Willems, educador musical belga, as canções são "meios sensíveis e eficazes para desenvolver a musicalidade e a audição interior" (PAREJO, 2013, p. 103). Willems ressalta a importância da escuta na preparação auditiva da criança, que engloba, entre outros aspectos, os "elementos melódicos: intervalo, escala e sentido tonal, imaginação retentiva e reprodutiva, memória melódica e audição relativa" (PAREJO, 2013, p. 96). Portanto, diversos códigos e conceitos musicais são assimilados intuitivamente, promovendo um fácil desenvolvimento da percepção auditiva, indispensável à performance de qualquer instrumento de cordas. Por essa razão, buscou-se transferir para o ensino de tais instrumentos os benefícios dessa utilização. A inclusão organizada e criteriosa de músicas do repertório brasileiro na rotina de estudo do aluno de cordas poderá favorecer a assimilação do conteúdo técnico-musical, do desenvolvimento de uma boa afinação e do aprendizado de mecanismos básicos de execução do instrumento. 
O ensino dos instrumentos de cordas por meio de canções folclóricas brasileiras enquadra-se no princípio do aprendizado da língua materna utilizado por Suzuki. Teoricamente, a familiarização da criança com o repertório brasileiro, a exemplo do aprendizado da língua, ocorreria durante a infância, naturalmente, pela tradição oral. Esse processo tornar-se-ia um facilitador porque uma das dificuldades com que o professor Suzuki se depara, na sua atividade docente, é convencer o aluno e seus pais da importância da escuta diária do repertório, princípio fundamental da metodologia Suzuki, indispensável à assimilação desse mesmo repertório (STARR, 2000, p. 7). Essa prática, comumente negligenciada pelo aluno, propicia um desenvolvimento técnico-musical mais rápido e eficiente.

Entretanto, percebe-se que, atualmente, as crianças não iniciadas musicalmente desconhecem grande parte das cantigas folclóricas brasileiras. Esse distanciamento da tradição musical brasileira por parte da nossa infância e, provavelmente, de seus pais, revela a necessidade de um resgate da cultura tradicional brasileira. Tal reaproximação fortalece e enriquece a abordagem de ensino proposta.

Se o contato da criança com essas cantigas não ocorrer espontaneamente nos ambientes familiar e escolar, essa lacuna pode ser preenchida nas aulas de musicalização infantil, que antecedem o ensino instrumental na maioria das escolas de música do país. Observou-se, pelos resultados de um teste de reconhecimento de cantigas do folclore brasileiro realizado em uma das etapas da pesquisa O Método Suzuki e a música tradicional mineira no ensino de violino, que mais de $60 \%$ das crianças testadas, matriculadas no Curso de $\mathrm{Mu}-$ sicalização da Escola de Música da Universidade do Estado de Minas Gerais, demonstraram familiaridade com 80 melodias $^{5}$ apresentadas, sendo 27 delas $^{6}$ reconhecidas por $100 \%$ das crianças (BORGES, 2011, p. 89).

\section{Considerações sobre as pesquisas}

O principal objetivo da pesquisa O Método Suzuki e a música tradicional mineira no ensino de violino foi desenvolver um material de estudo para violino que apresentasse qualidade, proporcionasse uma atmosfera de ensino prazerosa e promovesse a captação de um maior contingente de alunos, mantendo-os motivados no período da aprendizagem básica do instrumento (BORGES, 2007, p. 43).

Dois aspectos primordiais da didática instrumental, motivação e organização pedagógica, foram explorados utilizando-se canções folclóricas brasileiras ${ }^{7}$ e uma metodologia comprovadamente eficaz. O Método Suzuki foi a abordagem pedagógica escolhida devido à experiência da pesquisadora com essa metodologia de ensino, seus reconhecidos benefícios para o aluno e sua expansão pelo mundo.

Selecionou-se um repertório brasileiro específico, conhecido das crianças de Minas Gerais, com a finalidade de iniciar o aluno nos conceitos técnicos e musicais abordados nos dois primeiros volumes do repertório para violino do Método Suzuki (BORGES, 2007, p. 45). Na pesquisa posterior - O Método Suzuki e o folclore brasileiro no ensino dos instrumentos de cordas -, buscou-se ampliar para os outros instrumentos de cordas - viola, violoncelo e contrabaixo - a abordagem de ensino desenvolvida para o violino. Isto é, houve a proposta de introduzir os conceitos técnicos e musicais abordados nos dois primeiros volumes de repertório do Método Suzuki nos estudos de viola, violoncelo e contrabaixo. As condições de execução e organização didática do repertório folclórico de violino, desenvolvido na pesquisa anterior, foram mantidas. 
As etapas de trabalho, enumeradas a seguir, incluem os processos realizados nas duas pesquisas. Julgou-se esclarecedora a apresentação desses procedimentos para a compreensão da abordagem de ensino proposta.

Inicialmente, procedeu-se à identificação dos conceitos técnicos e musicais presentes nas peças do repertório Suzuki. Os conceitos do repertório para violino foram relacionados, tendo como base informações coletadas no livro The Suzuki Violinist, de William Starr (2000), anotações feitas em cursos de treinamento para professor Suzuki e a experiência pedagógica da pesquisadora. O repertório dos outros três instrumentos, viola, violoncelo e contrabaixo, foi analisado criteriosamente e comparado àquele do violino. Os conceitos do repertório Suzuki identificados e analisados incluíram: (1) golpes de arco; (2) arcadas e regiões de arco; (3) padrões de dedilhados; (4) forma de mão esquerda; (5) padrões rítmicos e melódicos; (6) mudanças de posição; (7) métrica de compasso; (8) tonalidade; e (9) estrutura formal.

$\mathrm{Na}$ primeira pesquisa, coletaram-se 302 e, posteriormente, selecionaram-se 285 canções folclóricas brasileiras para a aplicação de um teste de reconhecimento do folclore brasileiro. Seu objetivo foi identificar as cantigas mais conhecidas das crianças mineiras na faixa etária entre 5 e 12 anos, fase em que as instituições de música tradicionais comumente introduzem o ensino teórico e o instrumental ${ }^{8}$. A classificação das 285 melodias selecionadas norteou a pesquisadora no processo de seleção do repertório folclórico para o violino e na escolha de peças adicionais da pesquisa mais recente ${ }^{9}$.

Após a identificação das melodias mais conhecidas, iniciou-se o processo de seleção das cantigas do repertório brasileiro para violino, de acordo com a demanda técnico-musical do repertório Suzuki. Quando houve a possibilidade de escolha entre várias peças, a mais conhecida foi sempre privilegiada. Apesar das divergências entre o número e a seleção das peças dos repertórios de violoncelo e contrabaixo e das coletâneas de violino e viola, constatou-se que a utilização quase integral do repertório desenvolvido para violino, além de ser viável, poderia contribuir para a unidade da proposta pedagógica e para a elaboração de arranjos voltados para a prática da música de câmara.

$\mathrm{Na}$ adaptação didática das canções brasileiras para violino, as principais características melódicas e rítmicas das cantigas foram mantidas. Foram realizadas pequenas modificações no repertório brasileiro selecionado, com os objetivos de: possibilitar a abordagem dos conceitos técnicos da maneira mais ampla possível; propiciar o uso adequado do arco (distribuição e golpes de arco); e evitar técnicas de execução acima do nível do aluno (mudanças de posição, formas de mão esquerda e golpes de arco complexos) ${ }^{10}$.

As alterações em partitura incluíram: transposições, executadas a partir da canção original encontrada nas fontes bibliográficas ou fonográficas; simplificação de ritmos sincopados, para evitar mudanças de direção de arco muito rápidas e de difícil execução por parte dos alunos de nível básico; mudanças de métrica, que buscaram explorar mais amplamente a métrica ternária empregada no repertório Suzuki e pouco frequente no folclore brasileiro (BORGES, 2011, p. 87); padronização rítmica, para possibilitar o uso contínuo de colcheias, como ocorre nas peças do repertório Suzuki, Moto Perpetuo e Etude ${ }^{11}$; adaptação melódica, com o objetivo de evitar intervalos de difícil execução ou mudanças de corda indesejadas; adequação da duração de notas, para propiciar a execução de terminações de frases, golpes de arco e distribuição de arco; e acréscimos à partitura, possibilitando a inclusão de pontos técnicos, como ornamentos e harmônicos, ou passagens de transição, indispensáveis à elaboração de medleys ${ }^{12}$.

A última fase de ambas as pesquisas envolveu a elaboração de materiais didático-pedagógicos que englobaram a prática individual e a música de câmara. Essa elaboração 
incluiu a edição das partituras, com a definição de arcadas e dedilhados, a inclusão de dinâmicas e termos de expressão e a gravação de um DVD contendo uma seleção do repertório desenvolvido para a apresentação de resultados para a instituição financiadora do projeto de pesquisa.

\section{Descrição do repertório brasileiro}

O repertório brasileiro gerado nas pesquisas citadas integram a abordagem pedagógica proposta neste artigo. Portanto, é relevante abordar seus principais aspectos. No total, foram selecionadas, adaptadas e editadas 61 melodias folclóricas brasileiras por meio das quais foi possível introduzir com eficiência os pontos técnicos e musicais presentes nas peças do repertório Suzuki.

As peças estrangeiras foram suplementadas por uma ou mais cantigas brasileiras, apresentadas parcialmente ou na íntegra, dependendo do caráter, da duração, dos conceitos técnico-musicais e das características melódicas e rítmicas inerentes às canções recolhidas. A elaboração de medleys foi a solução encontrada para suplementar as peças do repertório Suzuki de maior duração. Essas peças cada vez mais longas colaboram com o desenvolvimento da resistência física e, principalmente, da memória do aluno.

Pelo fato de o repertório Suzuki de viola ser idêntico ao de violino ${ }^{13}$, a adaptação da coletânea brasileira demandou poucos ajustes. Todas as peças para violino foram transpostas para uma quinta abaixo, com o objetivo de se adequarem à tessitura da viola. As peças apresentadas para violino em lá maior, ré maior e sol maior aparecem para a viola em ré maior, sol maior e dó maior, respectivamente. Entretanto, verificou-se que o repertório de viola estrangeiro contou com a adição de duas peças no primeiro volume: French Folk Song (SUZUKI, 2009, p. 10) e Bohemian Folk Song (SUZUKI, 2009, p. 20). Essas peças são comumente utilizadas como material complementar ao estudo de violino. ${ }^{14}$ Portanto, optou-se por selecionar canções folclóricas brasileiras para explorar os conceitos técnico-musicais trabalhados nelas e adicioná-las ao repertório final de todos os instrumentos.

Os repertórios de violoncelo ${ }^{15}$ e contrabaixo ${ }^{16}$ do Método Suzuki diferem parcialmente daqueles do violino e da viola, e a ordem de apresentação das peças em comum aos repertórios foi modificada para atender às peculiaridades desses instrumentos. As principais mudanças realizadas na adaptação da coletânea brasileira final de violino para violoncelo e contrabaixo foram transposições para as mesmas tonalidades do repertório Suzuki desses instrumentos.

O material brasileiro final inclui as seguintes partituras: (1) partes individuais do instrumento - violino, viola, violoncelo e contrabaixo; (2) partes de acompanhamento de piano; (3) partes de duos para todo o repertório de cada instrumento; e (4) partitura e partes individuais para quinteto de cordas. Essa formação inclui violino I e II, viola, violoncelo e contrabaixo. ${ }^{17}$

Buscou-se incluir o maior número possível de peças da seleção de violino e viola nos repertórios de violoncelo e contrabaixo, com o objetivo de valorizar e maximizar a utilização do repertório brasileiro em atividades que envolvessem a prática da música de câmara em conjuntos variados. Os benefícios dessa prática camerística diversificada são bastante significativos para o instrumentista de cordas por ser essencial na sua formação e no seu desempenho dentro da orquestra - seu principal campo de trabalho. Dentre outros benefícios destacam-se: fixação e flexibilização do conteúdo aprendido, preparação para apresentações públicas e aumento do nível de motivação. 
As partes de piano foram desenvolvidas levando-se em consideração o tipo de escrita pianística utilizada por Suzuki nos seus dois primeiros volumes de repertório para violino - uma escrita simples, cuja mão direita frequentemente dobra a melodia ${ }^{18}$ e que não impõe dificuldades técnicas para o acompanhador que, em muitas ocasiões, poderá ser o próprio professor de instrumento, no caso de ele dominar a técnica básica do piano. A mão esquerda executa o acompanhamento propriamente dito: harmonias, figuras rítmicas e melódicas que dão o caráter desejado à peça.

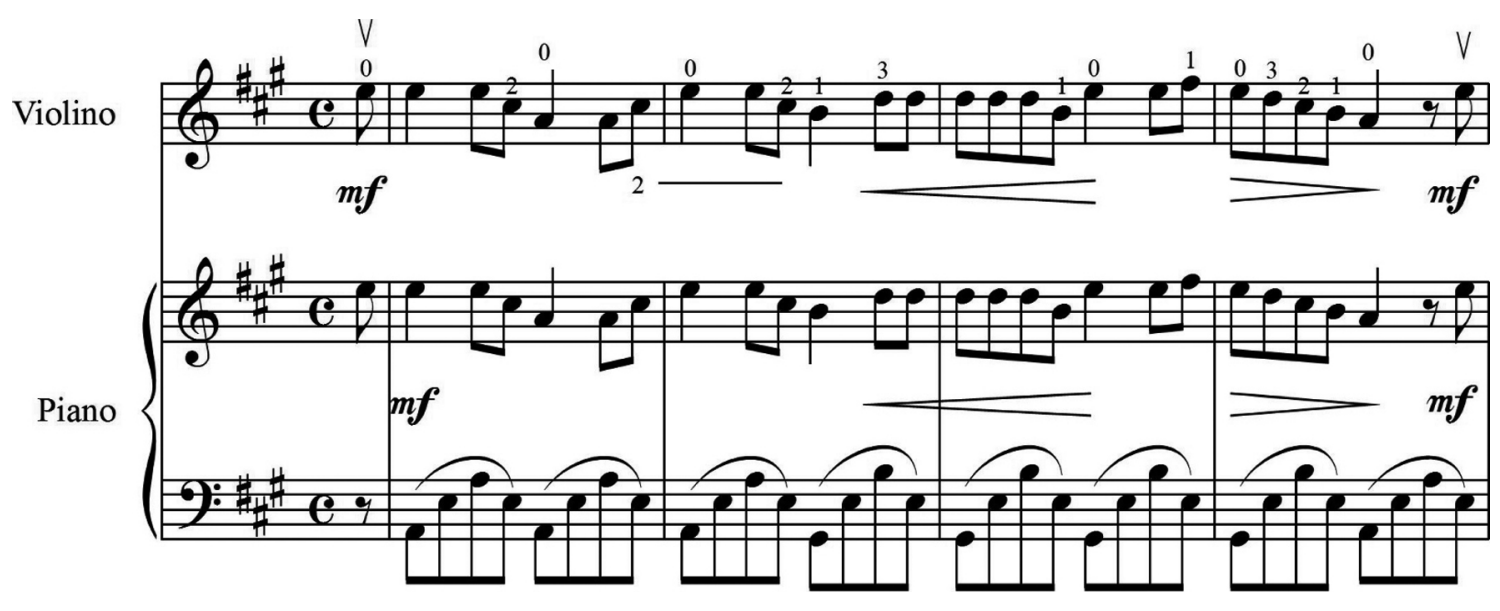

Exemplo 1: Se eu fosse um peixinho na versão para violino e piano.

O acompanhamento arpejado da mão esquerda do piano na peça Se eu fosse um peixinho procura descrever o movimento das ondas do mar.

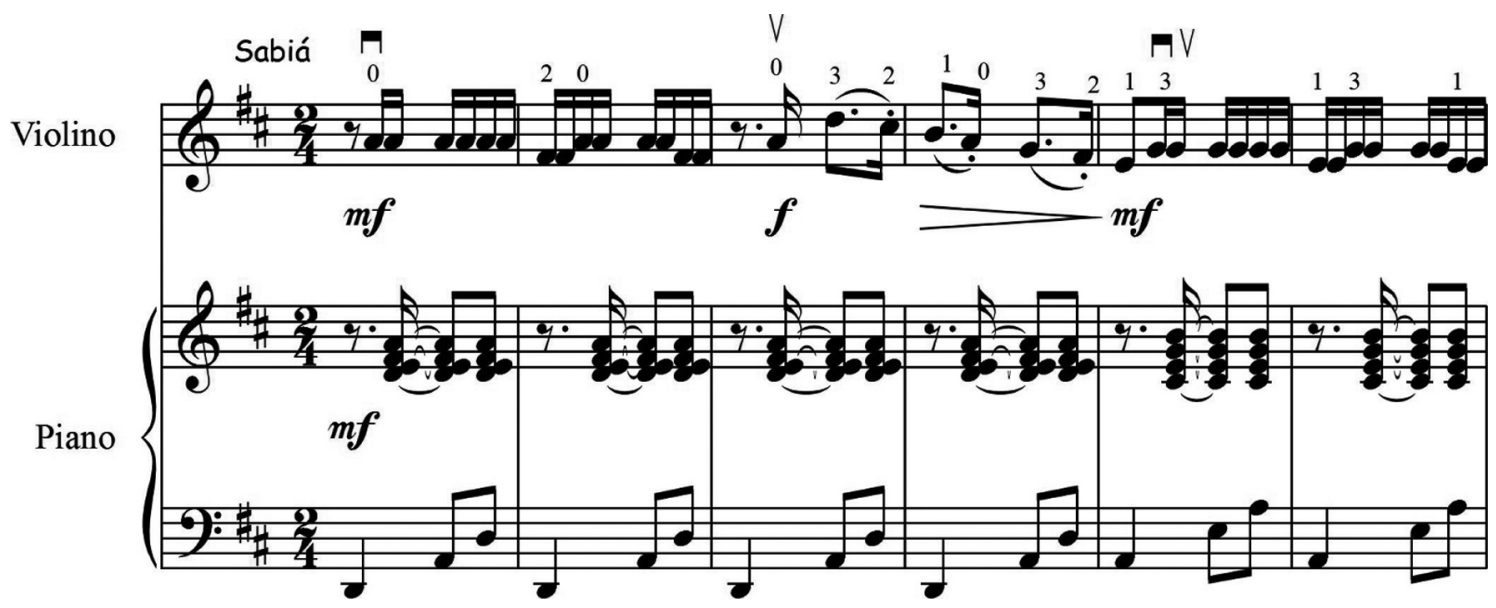

Exemplo 2: Sabiá na versão para violino e piano.

Já o acompanhamento de Sabiá busca adicionar a ela um caráter mais animado com a célula rítmica do baião (CAEF, 2016). A utilização dos duos em sala de aula possibilita maior contato do aluno com a prática da música de câmara. As partes do acompanhador visam a auxiliar o aluno na afinação e execução precisa dos padrões rítmicos explorados. Em alguns acompanhamentos, deu-se ênfase ao ritmo da melodia, à marcação da pulsação ou à subdivisão. 
Viola I

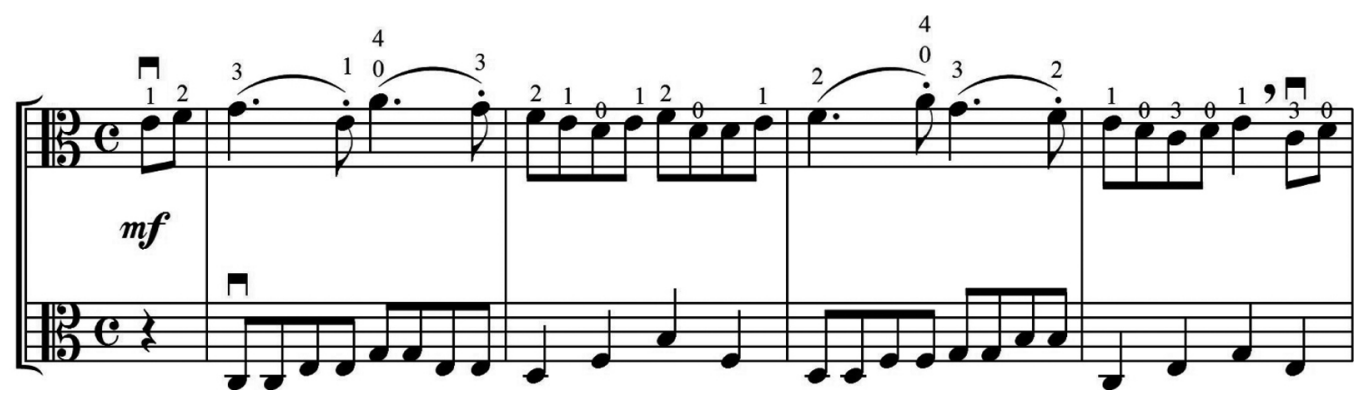

Exemplo 3: A subdivisão em colcheias tocada pela viola II no duo Carneirinho carneirão.

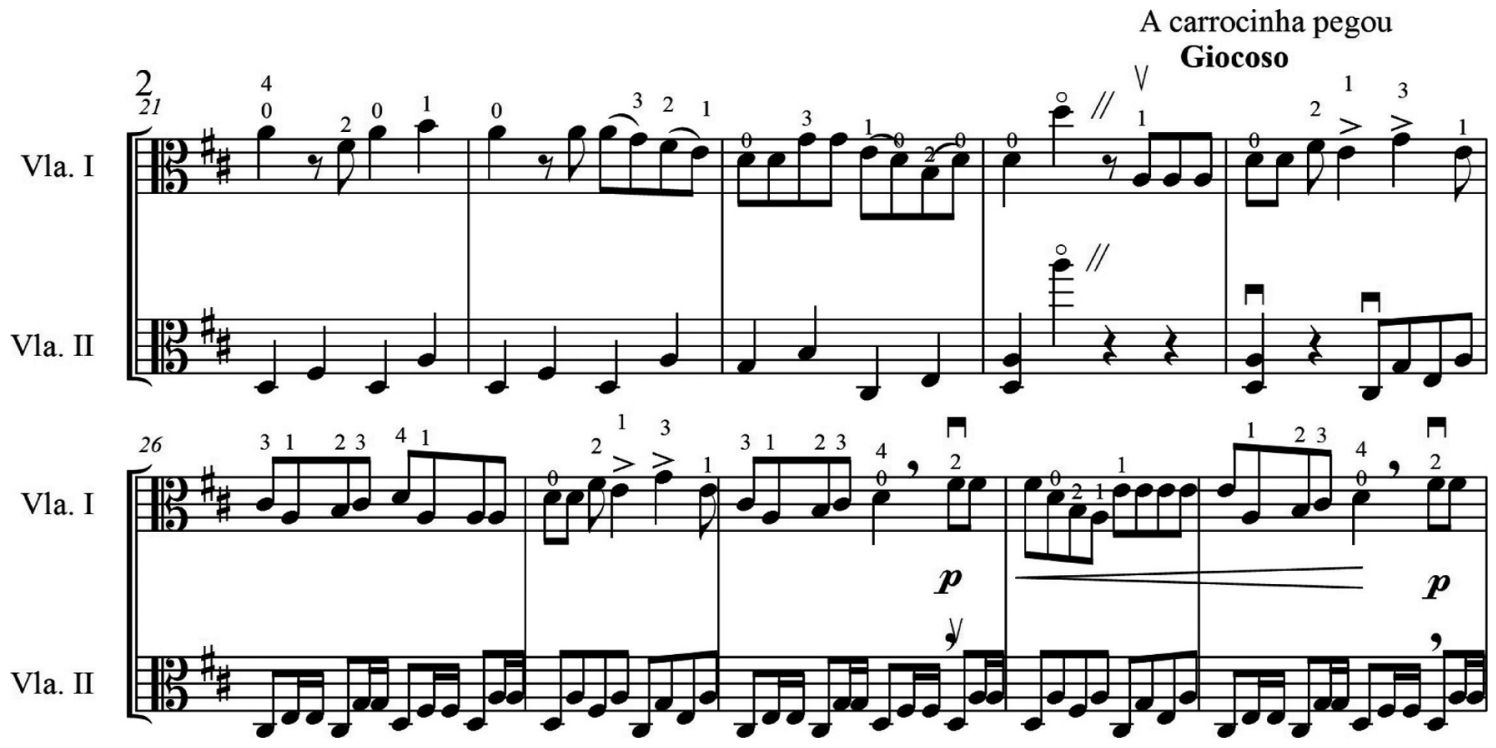

Exemplo 4: As síncopes são acompanhadas por colcheias no acompanhamento de viola no duo A carrocinha pegou.

A subdivisão auxilia na performance de ritmos pontuados, presentes em Carneirinho carneirão, síncopes, como aparecem em A carrocinha pegou e outros desafios rítmicos. Como ilustrado no exemplo n.5 abaixo, o violoncelista acompanhador toca a melodia da canção A barata diz que tem em uníssono com o aluno.

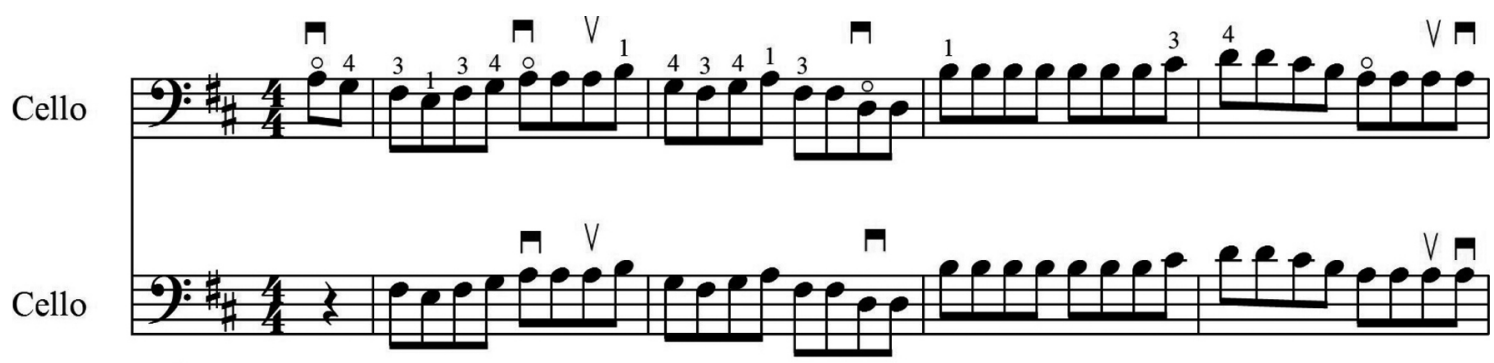

Exemplo 5: A barata diz que tem na versão para dois violoncelos.

Nessa cantiga, a afinação e a precisão rítmica são dificultadas pelo movimento constante do arco, necessário à execução das colcheias.

A execução dos quintetos envolve a leitura de notas e a aplicação da técnica aprendida nos dois volumes de estudo individual em situações diversas. Essas modificações incluem a execução das melodias em outras tonalidades, cordas, posições e dedilhados. Por essa razão, os quintetos foram desenvolvidos para serem utilizados após o aprendizado da leitura de notas ${ }^{19}$ e o término de cada volume de repertório em que a peça esteja inserida, possibilitando maior liberdade e criatividade na elaboração dos arranjos. 
Esse adiamento do uso dos quintetos também se faz necessário devido às diferentes tonalidades usadas no início do aprendizado de cada instrumento e no decorrer dos dois primeiros volumes de repertório. Portanto, para que cada naipe possa tocar o material temático, o que torna o arranjo mais atraente, todos os instrumentistas precisam dominar as tonalidades em que a cantiga foi apresentada para os demais instrumentos.

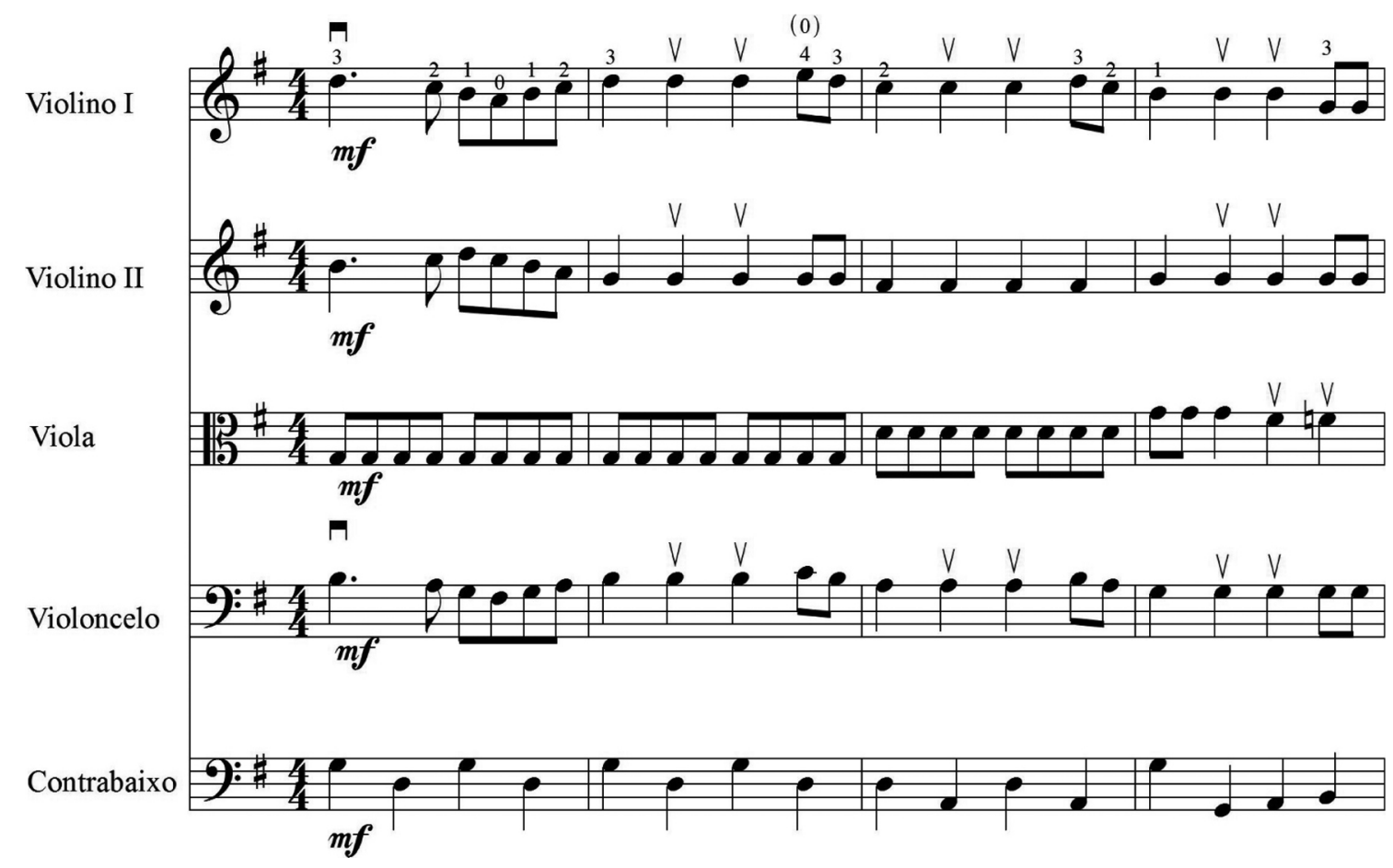

Exemplo 6: Quinteto de Atirei o pau no gato, compassos 1-4.

Pode-se observar na versão para quinteto de Atirei o pau no gato que a tonalidade utilizada é sol maior, e o material temático é compartilhado, inicialmente, pelo violino e pelo violoncelo.

A performance dos quintetos em atividades conjuntas, além de requerer maior domínio técnico por parte dos alunos e ser uma das principais fontes de motivação para a continuidade do estudo, sedimentará o conhecimento adquirido nas aulas individuais, possibilitará o treinamento da leitura e preparará o aluno para a prática de orquestra de uma forma lúdica.

Em 2015, o pesquisador envolvido no segundo projeto, professor doutor Valdir Claudino, teve a oportunidade de incluir em sua atividade docente alguns duos do repertório desenvolvido. Sua abordagem seguiu procedimentos que se julgaram mais apropriados ao ensino coletivo em seminários de performance para contrabaixistas. O trabalho com a turma se dividiu em quatro etapas. Na primeira, a turma foi dividida em duplas, que foram orientadas a estudar as partes de duas peças cada. Em seguida, cada dupla se apresentou para a turma. Na terceira etapa, todos os alunos aprenderam e executaram os quatro duos utilizados nessa dinâmica de aula. No último estágio, trocaram-se as vozes e, sob a orientação e supervisão do professor-pesquisador e do professor residente, os alunos se familiarizaram com os novos dedilhados, golpes de arco e arcadas. Os três primeiros estágios descritos acima foram repetidos com a nova distribuição de vozes.

Segundo Claudino, essa experiência trouxe aos alunos a oportunidade de trabalhar em suas técnicas individuais, na leitura, na prática camerística e na performance em público. Os alunos demonstraram familiaridade com as quatro canções folclóricas apre- 
sentadas, ${ }^{20}$ interesse e motivação no estudo e na execução para os colegas. Esses resultados podem ser considerados promissores para a aplicação da abordagem pedagógica proposta, visto que os desafios técnicos e musicais foram superados e a familiaridade com a cantiga mostrou ter facilitado a absorção desse material musical.

O fato de haver um vasto repertório em comum entre todos os instrumentos de cordas abre uma gama de possibilidades para sua aplicação, e a extensão dos benefícios poderá ser superior àqueles mensurados pelos pesquisadores. As necessidades de cada programa de cordas, a capacitação e a criatividade dos professores definirão a abordagem e os resultados da aplicação do repertório.

\section{Considerações sobre a proposta pedagógica}

Como exposto anteriormente, a abordagem pedagógica proposta envolve um conjunto de ações que busca um ensino de qualidade, eficiente, abrangente e motivador. Objetiva-se, desde o início do aprendizado, o desenvolvimento de uma série de conceitos, técnicas e habilidades que poderão trazer resultados significativos a longo prazo.

Além da utilização do repertório exclusivamente brasileiro, seguindo a abordagem de conceitos técnico-musicais introduzidos no repertório do Método Suzuki e do repertório camerístico, propõe-se a incorporação de inúmeros processos inerentes à metodologia Suzuki. Alguns deles estão relacionados à aplicação da filosofia, da metodologia ou da abordagem do repertório. Dentre esses princípios (LANDERS, 1995, p. 12), que também podem ser facilmente empregados em programas de ensino tradicional, destacam-se: ênfase na escuta, aprendizado inicial por imitação e sem a leitura de notas, performance de memória, aprendizado por meio de um repertório bem organizado, conceitos apresentados em ordem progressiva de dificuldade, constante revisão do repertório visando ao aprimoramento técnico-musical, aprendizado do repertório na ordem apresentada e sem omissões, domínio de uma peça antes de aprender a seguinte, respeito ao ritmo de desenvolvimento de cada criança, ênfase na prática lenta e na performance final em andamento correto, ênfase na performance constante e sistema de instrução que incorpora aulas individuais e coletivas.

A ênfase do Método Suzuki na qualidade de som se evidencia com as instruções apresentadas nos primeiros volumes de repertório e com os inúmeros exercícios de sonoridade chamados por Suzuki de Tonalização. A condução do arco e alguns processos de produção de som, como distribuição de arco e aplicação de pressão na ponta do arco, foram cuidadosamente observados na escolha e edição da coletânea brasileira.

De acordo com Rolland, a boa qualidade de som resulta do treinamento de movimentos corporais, como mencionado anteriormente. Rolland (1986) propõe inúmeras atividades com o objetivo de prevenir tensões musculares e desenvolver padrões de movimentos equilibrados, flexíveis e saudáveis para violinistas e violistas. Pretende-se incorporar na metodologia brasileira atividades que lidam com os seguintes aspectos da abordagem de ensino de Rolland: fortalecimento da musculatura das costas, suporte equilibrado do instrumento e o uso do peso da cabeça, posicionamento do instrumento, posição dos pés e transferência de peso entre eles, flexibilidade dos joelhos, liberdade de movimentos de ambos os braços e mãos e a execução de movimentos circulares. Várias demonstrações dos princípios e de atividades da metodologia de Rolland (2008) contidas no vídeo do projeto envolvem instrumentistas de queixeira, violoncelistas e contrabaixistas.

Acredita-se que a inserção de exercícios técnicos, escalas e arpejos relacionados com as tonalidades e as passagens técnicas de difícil execução das cantigas será fundamental para o aprendizado da técnica básica utilizada no repertório brasileiro. 


\section{Apresentação final do material pedagógico}

Seguindo o exemplo do material tradicionalmente utilizado no Método Suzuki, o kit de estudo brasileiro básico incluirá as partes individuais para cada instrumento de cordas, partes de acompanhamento de piano e gravação em DVD $^{21}$ de todas as peças de cada volume do repertório, o que permitirá a escuta diária desse repertório, sua execução simultânea pelo aluno e a observação dos padrões de movimento. Pretende-se incluir no livro do aluno todas as peças do repertório com acompanhamento da segunda voz, exercícios técnicos e atividades propostas. A apresentação das duas vozes, melodia principal e acompanhamento, em um sistema de duas pautas, facilitará a identificação de similaridades e diferenças entre as vozes e outros aspectos relevantes para a compreensão da peça, bem como permitirá a execução posterior desses acompanhamentos pelo aluno.

Além do kit básico, planeja-se disponibilizar as partituras e as partes dos arranjos para quinteto e um guia para o professor. Esse guia conterá os objetivos e instruções para a execução de cada peça do repertório; as finalidades e as etapas para a realização de todos os exercícios técnicos e as atividades propostas; e qualquer outra informação que se julgar pertinente à aplicação da metodologia durante o processo de publicação.

Pretende-se incluir instrumentos de percussão ou percussão corporal ${ }^{22}$ nos acompanhamentos de piano gravados em CD. Essa inclusão busca uma aproximação da vivência do aluno de instrumento atual pelo uso de ritmos populares que explorem a riqueza rítmica da música brasileira. Essa abordagem mais divertida e motivadora requererá uma análise cuidadosa do repertório para se definirem quais ritmos e instrumentos serão mais apropriados para esses acompanhamentos. A série britânica Violin Star, da ABRSM - Associated Board of the Royal Schools of Music (JONES, 2011), é um bom exemplo da incorporação de instrumentações e estilos musicais variados nos acompanhamentos gravados do repertório, que busca uma maior aceitação por parte de crianças e jovens.

\section{Aplicação da abordagem pedagógica}

Existem duas possibilidades para a aplicação dos métodos de estudo para violino, viola, violoncelo e contrabaixo. A primeira delas seria dentro do ensino tradicional, e a segunda, dentro de programas que seguem a metodologia Suzuki.

O objetivo do material didático é complementar e ampliar os benefícios do repertório Suzuki por meio de cantigas brasileiras e de um conjunto de abordagens internacionalmente respeitadas. Pressupõe-se que, após o aprendizado dos conceitos técnicos apresentados no repertório brasileiro, o aluno estará apto a praticar a peça correspondente do repertório Suzuki com maior desenvoltura. Cada habilidade desenvolvida poderá ser reforçada com o estudo das músicas do repertório estrangeiro.

Por outro lado, se o aluno estiver inserido em programas que aplicam a metodologia japonesa, o aprendizado e a memorização do repertório estrangeiro continuarão sendo mandatórios $^{23}$. Essa prática se faz obrigatória para a participação em eventos regionais, nacionais e internacionais do Método Suzuki. Nesses eventos, são oferecidos master classes e aulas individuais e coletivas, ocasiões em que o aluno é requisitado a tocar o repertório Suzuki de memória (BORGES, 2006, p. 33).

A proposta de utilização simultânea do conjunto de peças brasileiras e do repertório Suzuki não impede o uso independente dessas peças como repertório alternativo no ensino tradicional - aliás, essa é uma prática comum do professor de violino tradicional em 
relação ao repertório Suzuki. Pelo fato de algumas das canções folclóricas escolhidas serem populares em outros estados brasileiros, de apresentarem os pontos técnicos e musicais em ordem crescente de complexidade e de possibilitarem seu uso desvinculado do repertório Suzuki, essa seleção de peças brasileiras poderá ser utilizada amplamente, sobretudo nas regiões Sul e Sudeste, onde o cancioneiro folclórico engloba diversas cantigas em comum, como se pôde observar no processo de coleta das cantigas brasileiras.

\section{Considerações finais}

A abordagem de ensino proposta abrange importantes aspectos do desenvolvimento dos alunos de violino, viola, violoncelo e contrabaixo e está fundamentada em pesquisas substanciais e em uma vasta experiência docente, tanto no ensino tradicional quanto na metodologia Suzuki. A introdução precoce de princípios da performance do instrumento, juntamente com a utilização do repertório brasileiro poderão proporcionar um ensino de base consistente e enriquecedor, além de um desenvolvimento futuro mais rápido e frutífero.

A inclusão de princípios do Método Suzuki e de atividades baseadas na metodologia de ensino de Paul Rolland no material pedagógico proposto visa a preencher lacunas no processo de aprendizado do aluno brasileiro. Buscaram-se diversas maneiras de motivar esses jovens, seja por meio do repertório brasileiro, que foi elaborado de acordo com a progressão de conceitos técnicos de um método internacionalmente reconhecido, seja pelo tratamento camerístico, ou ainda pela instrumentação dos acompanhamentos sugeridos para ele. O repertório desenvolvido viabiliza a realização de apresentações públicas frequentes por proporcionar várias possibilidades de formações camerísticas. Caberá ao professor e à escola escolher o formato que melhor se adapte às habilidades do aluno e à infraestrutura disponível.

Em momento algum pensou-se em criar um "Suzuki brasileiro" ou substituir o Método Suzuki e seu repertório por uma seleção musical brasileira, por uma razão óbvia: ensinar por esse método não é apenas transferir o conhecimento técnico e musical do repertório. O professor Suzuki habilitado compreende os princípios filosóficos e metodológicos e busca aplicá-los, diariamente, em sua atividade docente. Espera-se, por meio da abordagem de ensino proposta e da publicação do material pedagógico, contribuir para a implementação de um cenário musical em que haja recrutamento mais amplo de alunos, menor desistência dos instrumentistas de corda e constante motivação no cotidiano de professores e alunos.

\section{Notas}

1 Essas pesquisas foram realizadas na Escola de Música da Universidade do Estado de Minas Gerais/Uemg, com o apoio da Fundação de Amparo à Pesquisa do Estado de Minas Gerais - Fapemig.

2 A literatura dos instrumentos de cordas geralmente utilizada no ensino básico inclui métodos de estudo tradicionais de origem francesa, alemã, inglesa e norte-americana. Essa observação baseia-se na experiência docente da pesquisadora e na literatura disponível no mercado brasileiro e internacional.

3 Observações realizadas no decorrer de aproximadamente 23 anos de experiência docente da autora, sendo 20 deles na Escola de Música da Universidade do Estado de Minas Gerais - Uemg.

4 O Método Suzuki é uma metodologia de ensino instrumental que alcançou grande sucesso internacional a partir de meados da década de 1960 e vem sendo aplicado em diversos países da Ásia, Europa e Américas (LANDERS, 1995, p. 6).

5 Dessas 80 melodias, 25 foram incorporadas ao repertório brasileiro.

6 Dessas 27 melodias, 11 foram incorporadas ao repertório brasileiro.

${ }^{7}$ Optou-se por nomear como canções folclóricas brasileiras todas as cantigas que são tradicionalmente cantadas no Brasil, não importando sua origem. 
${ }^{8}$ No total, foram testadas 72 crianças matriculadas no Curso de Musicalização Infantil da Escola de Música da Universidade do Estado de Minas Gerais.

9 A classificação das 80 cantigas mais conhecidas é apresentada no artigo intitulado As canções folclóricas brasileiras mais conhecidas em Minas Gerais: características e possibilidades de sua utilização na educação musical e seu uso no ensino dos instrumentos de cordas (BORGES, 2011, p. 89).

${ }^{10}$ As alterações realizadas são amplamente abordadas no artigo intitulado O Método Suzuki e o folclore brasileiro no ensino básico de violino (BORGES, 2007, p. 50).

${ }^{11}$ Moto perpetuo está incluída no primeiro volume de repertório Suzuki dos quatro instrumentos de cordas. A peça Etude aparece nos primeiros volumes dos repertórios de violino, viola e violoncelo e é apresentada no segundo volume de contrabaixo.

${ }^{12}$ Reunião de peças, o mesmo que pout-pourri.

${ }^{13}$ O primeiro volume de violino contém 17 peças (SUZUKI, 2007).

14 Informação adquirida no curso de preparação para professor Suzuki nível 1B, frequentado pela pesquisadora.

${ }_{15}$ O primeiro volume de violoncelo possui 17 peças (SUZUKI, 2007). O segundo volume de repertório apresenta 12 peças (SUZUKI, 2007).

${ }^{16}$ O primeiro volume de contrabaixo contém 13 peças (SUZUKI, 2002). O segundo volume de repertório apresenta 12 peças (SUZUKI, 2002).

17 As partes de quintetos poderão também ser utilizadas por orquestras de cordas.

${ }^{18}$ Esse dobramento da melodia acontece em todo o volume 1 e nas primeiras peças do segundo volume, variando de acordo com o instrumento.

19 Nos Estados Unidos, a leitura de notas é comumente introduzida ao final do primeiro volume ou no início do segundo. Informação adquirida no curso de preparação para professor Suzuki nível 1B, frequentado pela pesquisadora.

20 As canções folclóricas utilizadas foram Marcha soldado, Fui no Itororó, Peixe vivo e Atirei o pau no gato.

${ }^{21}$ Apesar de o aluno brasileiro provavelmente conhecer grande parte das peças brasileiras selecionadas, optou-se por gravar toda a coletânea para instrumento com acompanhamento de piano. Além de ser outro referencial significativo em adição à da tradição oral, a gravação viabiliza o uso desse material pedagógico em outros Estados, além de Minas Gerais.

${ }^{22}$ Sugestões de instrumentos de percussão ou percussão corporal poderão ser propostas no guia do professor para possível aplicação em aulas individuais ou coletivas e em apresentações públicas.

${ }^{23}$ A obrigatoriedade de se tocar todo o repertório constitui um dos princípios metodológicos do Método Suzuki (LANDERS, 1995, p. 17).

\section{Referências}

ALVES, Carolina V. Padrões físicos inadequados na performance musical de estudantes de violin. Dissertação de Mestrado. Escola de Música da Universidade Federal de Minas Gerais, 2008. Belo Horizonte: UFMG, 2008. 153p.

BORGES, Gláucia A. As canções folclóricas brasileiras mais conhecidas em Minas Gerais: características e possibilidades de sua utilização na educação musical e seu uso no ensino dos instrumentos de cordas. Modus, Belo Horizonte, ano 6, n. 9, p. 81-94, 2011.

2006.

. Shinichi Suzuki e a educação do talento. Modus, Belo Horizonte, ano 3, n. 3, p. 24-36,

. O Método Suzuki e o folclore brasileiro no ensino básico de violino. Modus, Belo Horizonte, ano 4, n. 4, p. 42-55, 2007.

BORGES-SCOGGIN, Gláucia A. A Study of the Pedagogy and Performance of String Instruments in Brazil and the Social, Cultural, and Economic Aspects Affecting Their Development. Tese de Doutorado. Escola de Música da University of Iowa, 1993. Iowa: UI, 1993. 414p.

CENTRO DE ARTES E EDUCAÇÃO FÍSICA (CAEF). Padrão de acompanhamento baião: conteúdo. Disponível em: <http://prolicenmus.ufrgs.br/repositorio/moodle/material_integrador/teclado/un51_teclado_un51_conteudo.pdf>. Acesso em: 20 jan 2016. 
JONES, Edward H. Violin Star: Volume 1. England: ABRSM Publishing, 2011.

LANDERS, Ray. The Talent Education School of Shinichi Suzuki: an analysis. 4. ed. Princeton: Daniel Press, 1987, 192 p.

PAREJO, Enny. Edgar Willems: um pioneiro da educação musical. In: MATEIRO, Teresa; ILARI, Beatriz (Org.). Pedagogias em Educação Musical. Curitiba: Intersaberes, 2013. p. 89-123.

ROLLAND, Paul. The Teaching of Action in String Playing. 1. ed. rev. [S.l.]: Boosey and Hawkes, 1986, 214p.

. The Teaching of Action in String Playing. Produzido por Peter Rolland. DVD, 201 min. [S.l.]: RSRA, 2008.

SCOGGIN, Gláucia B. A Pedagogia e a Performance dos Instrumentos de Cordas no Brasil: um passado que ainda é realidade. Per Musi, Belo Horizonte, v. 7, p. 25-36, 2003.

SILVA, Walênia M. Zoltán Kodály: alfabetização e habilidades musicais. In: MATEIRO, Teresa; ILARI, Beatriz (Org.). Pedagogias em Educação Musical. Curitiba: Intersaberes, 2013. p. 55-87.

STARR, William. The Suzuki Violinist: a guide for teachers and parents. 2. ed. Miami: Summy-Bichard Music, 2000, 160p.

SUZUKI, Shinichi. Nurtured by Love: the classic approach to talent education. Suzuki. 2. ed. Athens: Ability Development Press, 1983, 108p.

. Suzuki Bass School: Volume 1. Bass Part. Revised edition. Van Nuys: Alfred Music Publishing, 2014.

. Suzuki Bass School: Volume 2. Bass Part. Revised edition. Van Nuys: Alfred Music Publishing, 2008.

. Suzuki Cello School: Volume 1. Cello Part. Revised edition. Van Nuys: Alfred Music Publishing, 2014.

. Suzuki Cello School: Volume 2. Cello Part. Revised edition. Van Nuys: Alfred Music Publishing, 2014.

. Suzuki Viola School: Volume 1. Viola Part. Revised edition. Van Nuys: Alfred Music Publishing, 2013.

. Suzuki Viola School: Volume 2. Viola Part. Van Nuys: Alfred Music Publishing, 2013.

. Suzuki Violin School: Volume 1. Violin Part. Revised edition. Van Nuys: Alfred Music Publishing, 2013.

. Suzuki Violin School: Volume 2. Violin Part. Revised edition. Van Nuys: Alfred Music Publishing, 2014.

Gláucia de Andrade Borges - Doutora em Música pela University of Iowa, onde se aperfeiçoou com o Professor Leopold La Fosse. Professora especializada no Método Suzuki pela Suzuki Association of the Americas, participou de cursos sob a orientação dos professores John Kendall e William Starr. Lecionou na Preucil School of Music e é professora da Universidade do Estado de Minas Gerais - Uemg desde 1996. Integrou a Orquestra Filarmônica de Minas Gerais e atua como violinista na Orquestra de Câmara do Sesiminas e na Orquestra Sinfônica de Minas Gerais. 